\title{
Root causes of elective surgical case cancellation in Ethiopia: a systematic review and meta-analysis
}

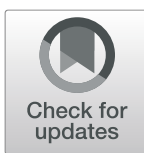

\author{
Yeneabat Birhanu ${ }^{1 *}$, Aklilu Endalamaw ${ }^{2}$ and Aynalem Adu ${ }^{1}$
}

\begin{abstract}
Background: Cancellation of elective surgical operation recognized as a major cause of emotional trauma to patients as well as their families. In Ethiopia, prevalence and root causes for elective surgical case cancellation varies from time to time in different settings. This systematic review and meta-analysis aimed to find the pooled prevalence and root causes for elective surgical case cancellation in Ethiopia.

Methods: The databases for the search were Web of Science, PubMed, and Google Scholar. The last literature search was performed on February 8, 2020. To assess publication bias Egger's regression analysis was applied. The pooled estimation was estimated using random-effects model meta-analysis. Subgroup analysis was also done based on the root causes of surgical case cancellation.

Results: This meta-analysis included a total of 5 studies with 5591 study participants. The pooled prevalence of elective surgical case cancellation was $21.41 \%$ (95\% Cl: 12.75 to 30.06\%).

Administration-related reason (34.50\%) was the most common identified root cause, followed by surgeon (25.29\%), medical (13.90\%), and patient-related reasons (13.34\%).

Conclusion: The prevalence of elective surgical case cancellation was considerable. The most common root cause for elective surgical case cancellation was administration-related reasons, followed by the surgeon, medical and patient-related reasons. The causes for the surgical cancellations are potentially preventable. Thus, efforts should be made to prevent unnecessary cancellations through careful planning.
\end{abstract}

Keywords: Cancellation, Elective surgery, Ethiopia

\section{Background}

Elective surgical case cancellation refers to a scheduled surgical procedure that not performed on a given day [1]. It has been a long-standing problem for healthcare organizations across the world [2]. Many patients could not receive elective surgery as per the schedule upon the waiting list [3].

Most hospitals invest resources to support operating suites. However, there is a concern of unanticipated

\footnotetext{
* Correspondence: birhanuyeneabat@gmail.com

'Department of Surgical Nursing, School of Nursing, College of Medicine and Health Sciences, University of Gondar, Gondar, Ethiopia

Full list of author information is available at the end of the article
}

cancellation of scheduled surgery [4]. In developing countries, cancellation of elective surgical operation is a common phenomenon [5].

Planned surgery cancellation is a well-recognized reflects of inefficiency in health care and/or service management [6]. It contributes to frustration and mental stress to the patients and their families [7]. It also increases the waiting of patients [8], surges the economic burden due to extended hospital stays $[9,10]$, and increases the risk of in-hospital death [11]. There are many reasons for the cancellation of elective surgical cases but they might differ from hospital to hospital [12]. Unexpected cancellations of planned surgery divided

(c) The Author(s). 2020 Open Access This article is licensed under a Creative Commons Attribution 4.0 International License, which permits use, sharing, adaptation, distribution and reproduction in any medium or format, as long as you give appropriate credit to the original author(s) and the source, provide a link to the Creative Commons licence, and indicate if changes were made. The images or other third party material in this article are included in the article's Creative Commons licence, unless indicated otherwise in a credit line to the material. If material is not included in the article's Creative Commons licence and your intended use is not permitted by statutory regulation or exceeds the permitted use, you will need to obtain permission directly from the copyright holder. To view a copy of this licence, visit http://creativecommons.org/licenses/by/4.0/ The Creative Commons Public Domain Dedication waiver (http://creativecommons.org/publicdomain/zero/1.0/) applies to the data made available in this article, unless otherwise stated in a credit line to the data. 
into avoidable and unavoidable cancellations [1]. Scheduling errors, equipment shortages, and inadequate preoperative evaluation are avoidable cancellations. Unavoidable cancellations are emergency encounters and unexpected changes in the patient's medical status [13]. Different literature suggested that by improving the planning most cancellations are avoidable. It has also suggested that patients themselves should receive notification early about their operation day and a reminder of their appointment [14]. Involving patients in such ways may increase their satisfaction with treatment decisions during initial consultations, which is a strong predictor of attendance for surgery [15].

Based on a study in Hong Kong China, reported surgical case cancellation was 7.6\% [16]. Similarly 11\% in Kingdom of Saudi Arabia [17], 3.6\% in Jordan [18], 1.87\% in Iran [19], and 20.8\% in Sub-Saharan Africa [20]. Variety of root causes listed for the cancelled operations. Of these, administrative-related accounted $30.4 \%$ [18] to $84.8 \%$ [21], patients' related accounted $25.9 \%$ [17] to $68.28 \%$ [22], medical-related reasons and surgeon-related reasons accounted $38.2 \%$ [18], and 28\% [23] respectively.

In Ethiopia, different primary studies have been conducted to determine the prevalence for elective surgical case cancellation and root causes. The proportion of elective surgical case cancellation was found in the range between 8.9 to $33.9 \%$ [24, 25] in the Ethiopian setting. Discrepancies between studies make it difficult to generalize the national estimation. Having national representative data is real to underpin effective management strategies. Thus, there is a need to estimate elective surgical case cancellation at the country level. This systematic review and meta-analysis aimed to find the pooled prevalence of elective surgical case cancellation. Besides, it explores root causes for elective surgical case cancellation in the Ethiopian setting. The review question was what are the prevalence of and root causes for elective surgical case cancellation in Ethiopia?

\section{Methods \\ Reporting}

We reported the results of this meta-analysis according to the Preferred Reporting Items for Systematic Reviews and Meta-analyses (PRISMA) guideline [26] (Additional file 1 research checklist).

\section{Literature search}

We searched Web of Science, PubMed, and Google Scholar databases. The terms for the search were pre-defined for a comprehensive search strategy. These included all fields within records and Medical Subject Headings (MeSH terms). In the Boolean operator, within each axis, we combined keywords with the "OR" operator. Then we linked the search strategies for the two axes with the "AND" operator. The search terms used for the search were "surgical case cancellation" OR "elective surgical case cancellation" AND "prevalence" OR "magnitude" AND reasons of surgical case cancellation AND "Ethiopia". The specific searching detail in PubMed with MeSH terms was ("magnitude of surgical case cancellation" [MeSH Terms] OR "magnitude of elective surgical case cancellation" [MeSH Terms] OR "surgical case cancellation" [MeSH Terms] OR "elective case cancellation"[MeSH Terms] AND "prevalence" [All Fields])OR "magnitude"[MeSH Terms] AND reasons of surgical case cancellation [All Fields]) AND ("Ethiopia"). The last literature search was performed on February 8, 2020. The publication year of the studies was not limited during the search.

\section{Study selection}

We exported retrieved studies to Endnote version 7 (Thomson Reuters, London) reference manager to remove duplicated studies.

The retrieved articles were screened according to predefined inclusion and exclusion criteria. Discussion and/ or involvement of the third reviewer resolved disagreements between two reviewers.

\section{Eligibility criteria Inclusion criteria}

Included studies were 1) articles that reported about the prevalence of elective surgical case cancellation and/or reasons for elective surgical case cancellation.2) studies published in English, and 3) studies conducted in Ethiopia before 02/08/2020. We did not limit the publication year of studies during the search.

\section{Exclusion criteria}

Articles available without full-text, qualitative studies, any reviews, commentaries, consultants' corners, letters, and conference abstracts were excluded.

\section{Quality assessment}

We used Joanna Brigg's Institute (JBI) quality appraisal criteria [27]. It is the assessment tool used to check the quality of each article. The tool consists of nine major items. The first item is appropriate to the sample frame. The second is the appropriate sampling technique. The third is the adequacy of the sample size. The fourth is a description of the study subjects and settings. The fifth is enough coverage of data analysis. The sixth is the validity of the method for identification of the condition. The seventh item is a standard and reliable measurement for all participants. The eighth is the appropriateness of statistical analysis. And the last item is adequacy and management of response rate. Studies considered low-risk when it would fit 5 or above quality assessment checklists.

\section{Data extraction}

Three authors extract the data. Data extracted from each article were first author, the geographical location of the 
study, publication year, study design, study population, sample size, the prevalence of and root causes for cancellation of elective surgery.

\section{Outcome measurement}

This systematic review and meta-analysis have two outcomes. Firstly, to determine the prevalence of elective surgical case cancellation in Ethiopia calculated as dividing the number of elective surgical patients but whom surgical cases canceled to the total number of patients multiply by 100. A total number of patients refer to elective surgical patients in the study period. Secondly, to identify the root causes for elective surgical case cancellation.

\section{Data analysis}

The required data were collected using a Microsoft Excel 2010 workbook form. Then, the STATA Version11 software was used to analyze the data. we used a weighted inverse variance random-effects model [28] to estimate the pooled prevalence. The $\mathrm{I}^{2}$ statistics was employed to assess the percentage of total variation across studies [29]. $\mathrm{I}^{2} \leq$ $25 \%$ suggested more homogeneity, $25 \%<\mathrm{I}^{2} \leq 75 \%$ suggested moderate heterogeneity, and $\mathrm{I}^{2}>75 \%$ suggested high heterogeneity [29]. Egger's regression test was also applied to assess publication bias [30]. Furthermore, we carried out the subgroup analysis based on the root causes for elective surgical case cancellation.

\section{Results}

A literature search of the databases yielded a total of 81 publications. Among these, 76 disregarded due to abstracts and titles that were unfit to the outcome of interest. A total of five eligible studies [24, 25, 31-33] with 5591 study participants were accessed for analysis of prevalence. Of these, three studies [24, 25, 33] with 3379 subjects were identified for analysis of root causes because the remaining two did not report about the root causes of elective surgery cancellation (Fig. 1).

\section{Characteristics of included studies}

The range of publication year for included studies was from 2015 to 2020. We found three studies in Addis Ababa [24, 25, 31], one in Oromia [32], one in Southern Nation, Nationalities, and People Region (SNNPR) [33]. All included studies were done by using the crosssectional study design (Table 1 ).

Three of the included studies [24, 25, 33] reported reasons for elective surgical case cancellation (Table 2).

\section{Quality assessment result}

We assessed of studies with JBI quality appraisal checklists. Based on this, none of the included studies was poor quality status.

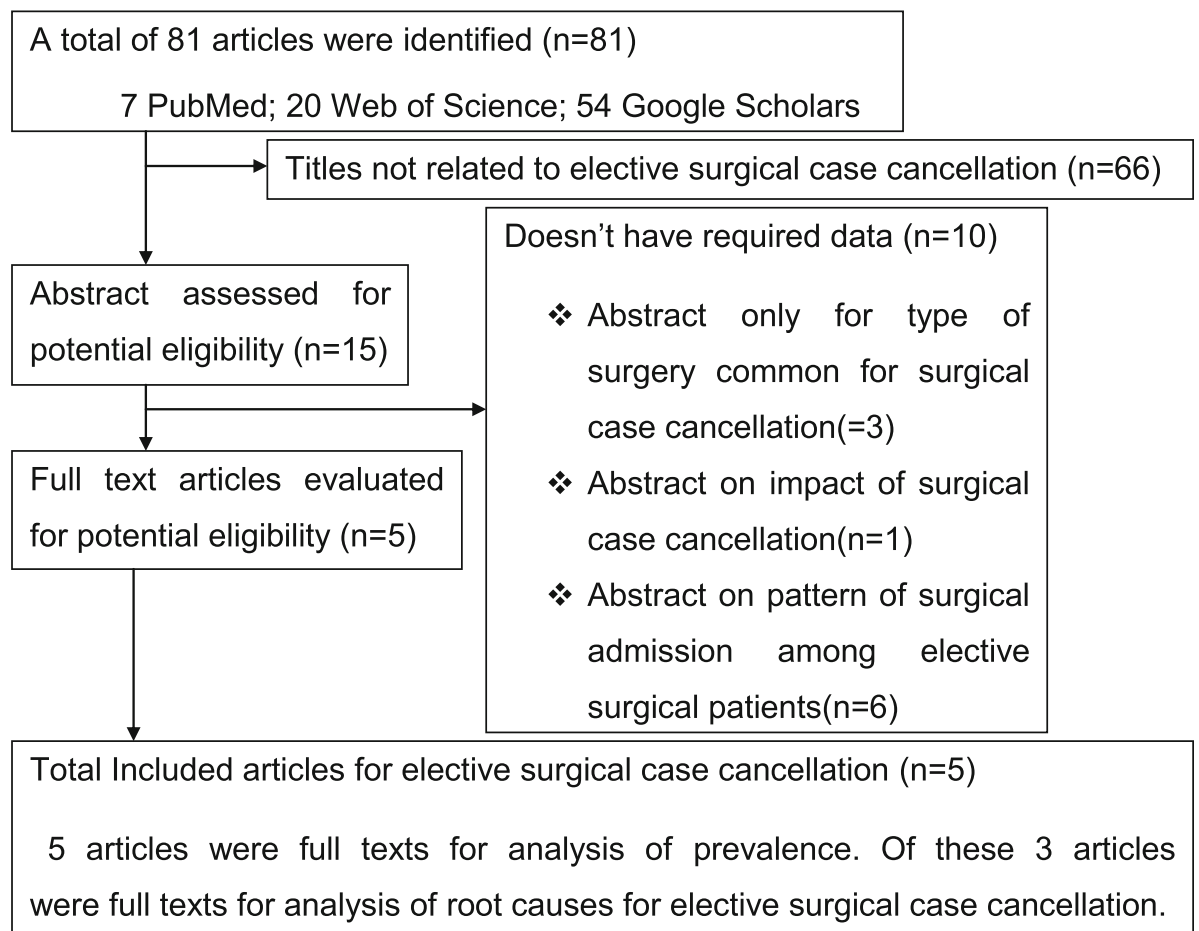

Fig. 1 Flow chart of the literature search for the articles included in a meta-analysis of elective surgical case cancellation 
Table 1 Characteristics of included studies in the meta-analysis for elective surgical case cancellation

\begin{tabular}{|c|c|c|c|c|c|c|}
\hline Author/Year & Study year & Region & Study design & Sample size & Prevalence & Study population \\
\hline Ayele AS et al./2019 [25] & February 1 to March 1, 2016 & Addis Ababa & Cross-sectional & 369 & 33.9 & All elective surgical patients \\
\hline Desta M et al./2018 [33] & March 1 to 30, 2018 & SNNPR & Cross-sectional & 462 & 31.6 & All elective surgical patients \\
\hline $\begin{array}{l}\text { Haile } M \text { and Desalegn } \\
\text { N/2015 [32] }\end{array}$ & February 1 to June 30, 2014 & Oromia & Cross-sectional & 1438 & 23 & All elective surgical patients \\
\hline Bekele M et al./2020 [24] & $\begin{array}{l}\text { March 1, } 2018 \text { to February } \\
28,2019\end{array}$ & Addis Ababa & Cross-sectional & 2548 & 8.9 & All elective surgical patients \\
\hline $\begin{array}{l}\text { Gebresellassie HW and } \\
\text { Tamerat G/2019 [31] }\end{array}$ & June 1, 2016 to May 30, 2017 & Addis Ababa & Cross-sectional & 774 & 10.7 & All elective surgical patients \\
\hline
\end{tabular}

\section{Meta-analysis}

The absence of publication bias was assessed with Egger's regression test $(p=0.062)$, which showed that no publication bias.

The pooled prevalence of elective surgical case cancellation was $21.41 \%$ (95\% CI 12.75 to $30.06 \%)$ (Fig. 2).

The pooled result of root causes for cancellation of elective surgery from three studies [24, 25, 33] showed that administration-related reason $(34.50 \%)$ was most prevalent followed by surgeon-related reasons (25.29\%), medical-related reasons (13.90\%), and patient-related reasons (13.34\%) (Fig. 3).

\section{Discussion}

There are no objective benchmarks for surgical cancellation rates. But reports under 5\% are generally recommended [34]. According to this meta-analysis, the estimation of elective surgical case cancellation was $21.41 \%(12.75,30.06)$ in Ethiopia. This is comparable with the study conducted in Sub-Saharan Africa [20] and Sudan [22]. Reasons for elective surgical case cancellation are almost similar in developing countries [20]. Besides, management strategies or surgical settings might be similar in developing countries. However, the current study's finding is lower than a study conducted in Nigeria [23], Uganda [35] and Malawi [21]. This

Table 2 Characteristics of included studies in the meta-analysis for the root causes of elective surgical case cancellation

\begin{tabular}{|c|c|c|c|c|c|c|c|}
\hline Author/Year & Study year & Region & $\begin{array}{l}\text { Study } \\
\text { design }\end{array}$ & $\begin{array}{l}\text { Cancelled elective } \\
\text { surgical cases }\end{array}$ & Root causes & Prevalence & Study population \\
\hline \multirow{5}{*}{$\begin{array}{l}\text { Ayele AS et al./ } \\
2019 \text { [25] }\end{array}$} & \multirow{5}{*}{$\begin{array}{l}\text { February } 1 \text { to } \\
\text { March 1, } 2016\end{array}$} & \multirow{5}{*}{$\begin{array}{l}\text { Addis } \\
\text { Ababa }\end{array}$} & \multirow[t]{5}{*}{ Cross-sectional } & \multirow[t]{5}{*}{125} & Patient-related reasons & 13.6 & \multirow{5}{*}{$\begin{array}{l}\text { All elective surgical } \\
\text { patients }\end{array}$} \\
\hline & & & & & Medical-related reasons & 12 & \\
\hline & & & & & $\begin{array}{l}\text { Administration- related } \\
\text { reasons }\end{array}$ & 30.4 & \\
\hline & & & & & Surgeon-related reasons & 42.4 & \\
\hline & & & & & Emergency case priority & 1.6 & \\
\hline \multirow{6}{*}{$\begin{array}{l}\text { Desta } M \text { et al./ } \\
2018 \text { [33] }\end{array}$} & \multirow{6}{*}{$\begin{array}{l}\text { March } 1 \text { to } \\
30,2018\end{array}$} & \multirow[t]{6}{*}{ SNNPR } & \multirow[t]{6}{*}{ Cross-sectional } & \multirow[t]{6}{*}{146} & Patient-related reasons & 18.4 & \multirow{6}{*}{$\begin{array}{l}\text { All elective surgical } \\
\text { patients }\end{array}$} \\
\hline & & & & & Medical-related reasons & 11.6 & \\
\hline & & & & & Surgeon-related reasons & 23.4 & \\
\hline & & & & & Emergency case priority & 11.6 & \\
\hline & & & & & $\begin{array}{l}\text { Administration- related } \\
\text { reasons }\end{array}$ & 21 & \\
\hline & & & & & Anesthesia-related reasons & 14 & \\
\hline \multirow[t]{6}{*}{$\begin{array}{l}\text { Bekele } M \text { et al./ } \\
2020 \text { [24] }\end{array}$} & \multirow[t]{6}{*}{$\begin{array}{l}\text { March 1, } 2018 \text { to } \\
\text { February 28, } 2019\end{array}$} & \multirow[t]{6}{*}{$\begin{array}{l}\text { Addis } \\
\text { Ababa }\end{array}$} & \multirow[t]{6}{*}{ Cross-sectional } & \multirow[t]{6}{*}{226} & $\begin{array}{l}\text { Administration- related } \\
\text { reasons }\end{array}$ & 52 & \multirow[t]{6}{*}{$\begin{array}{l}\text { All elective surgica } \\
\text { patients }\end{array}$} \\
\hline & & & & & Surgeon-related reasons & 11.1 & \\
\hline & & & & & Emergency case priority & 7.1 & \\
\hline & & & & & Anesthesia-related reasons & 2.7 & \\
\hline & & & & & Medical-related reasons & 17.7 & \\
\hline & & & & & Patient-related reasons & 9.4 & \\
\hline
\end{tabular}




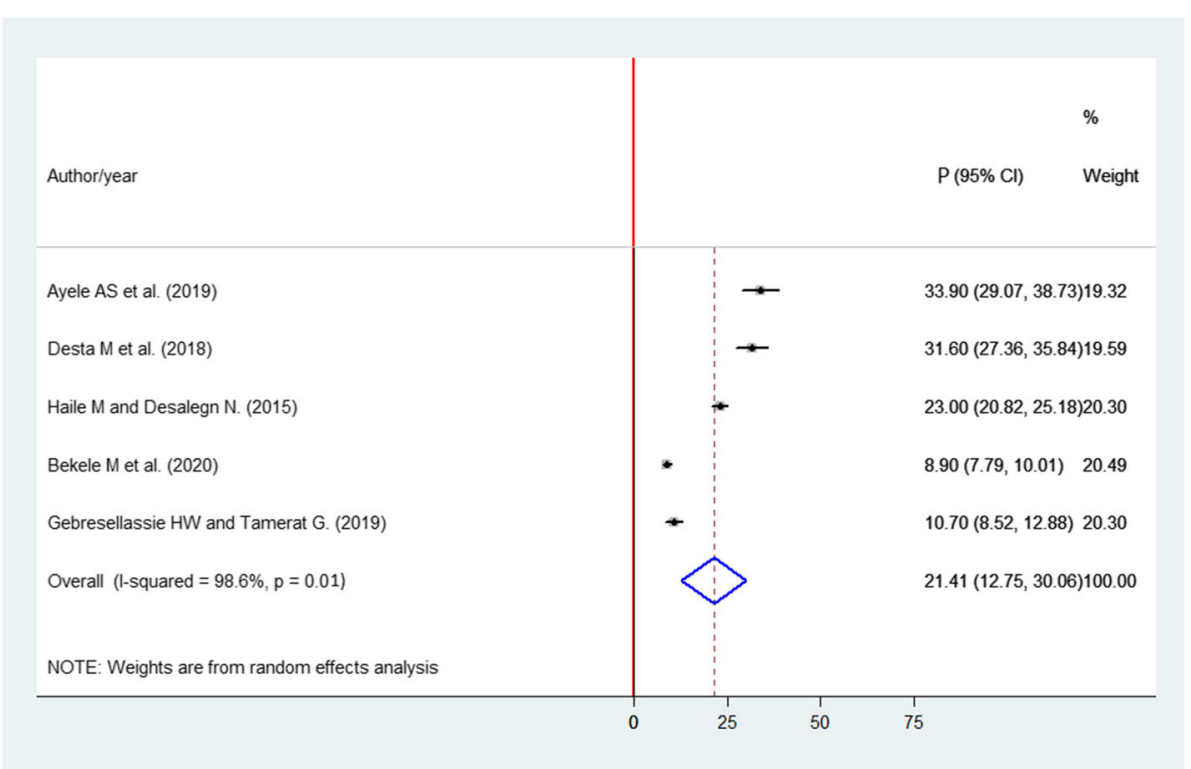

Fig. 2 Forest plot of prevalence with corresponding $95 \% \mathrm{Cls}$ of the five studies on elective surgical case cancellation. The midpoint and the length of each segment indicated prevalence and a $95 \% \mathrm{Cl}$. The diamond shape showed the combined prevalence of all studies

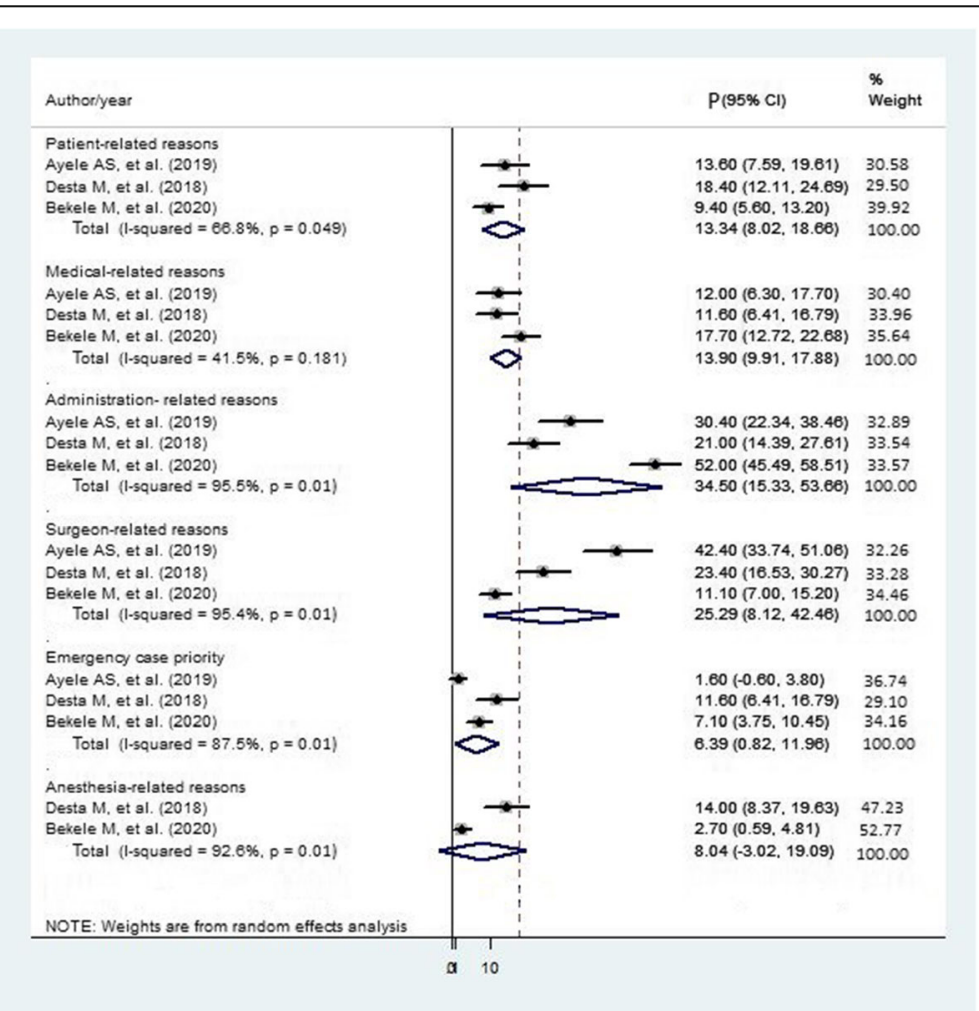

Fig. 3 Forest plot of prevalence with corresponding $95 \%$ Cls of three studies for the root causes of elective surgical case cancellation. The midpoint and the length of each segment indicated prevalence and a $95 \% \mathrm{Cl}$. The diamond shape showed the combined prevalence of all studies 
discrepancy might be due to findings of elective surgery cancellation vary widely because of study design; type of hospital, country, capacity, and patient type (inpatients vs. outpatients). Evidence shows that surgical case cancellation rates vary because of a lack of a standard definition, different patient populations and study methodology [36]. The current finding is higher than the study from Hong Kong China [16], the Kingdom of Saudi Arabia [17], and Jordan [18]. This difference might be due to poor hospital administration strategies. Evidence shows that lack of materials, surgeons delay, the patient not fully prepared, unperformed preliminary examinations, lack of beds in intensive care, inadequate administrative planning are indicators of poor hospital administration strategies [37]. This could cause the cancellation of elective surgical [10]. But not effective utilization of available resource hours, such as trained staff, appropriate facilities, equipment, good communication, and operational layout [38].

Based on the estimation of the root causes for elective surgical case cancellation, the most common identified cause was administration-related reason. The same report from the Kingdom of Saudi Arabia [17], Jordan [18], Uganda [35], and Malawi [21] showed that administration-related reasons found the most common causes of elective surgical case cancellation. This might be due to the reality is that surgical case cancellation can result in the financially under-utilization of theatres [2]. So, during the surgical procedure, it could cause a shortage of surgical materials in the hospital setting that makes challenge to run the activities. This finding helps healthcare policy and/or decision-makers to consider elective surgical case cancellation prevention strategies.

\section{Conclusion}

In this finding, the prevalence of elective surgical case cancellation was considerable. The most common root causes for elective surgical case cancellation was administration-related reasons followed by surgeonrelated, medical-related, and patient-related reasons. The causes for the cancellations are potentially preventable. Thus, efforts should be made to prevent unnecessary cancellations through careful planning. It means quality improvement strategies are necessary for surgical specialties that are susceptible to procedure cancellations caused by administrative reasons.

\section{Supplementary Information}

The online version contains supplementary material available at https://doi. org/10.1186/s13037-020-00271-5.

Additional file 1. Research checklist.

\section{Abbreviations}

Cl: Confidence Interval; SNNPR: Southern Nations and Nationalities of People Region

\section{Acknowledgments}

Not applicable.

\section{Authors' contributions}

YB: Design and planning of the study, review of the literature. More to the point $Y B$ contributes data analysis and drafting manuscript. AE: literature review, and data collection. AA: Took part to realize statistical analysis. All authors have read and approved the manuscript.

\section{Funding}

There is no fund received from any fund agency.

\section{Availability of data and materials}

No need for more data. All information stated in the manuscript and, its supplementary information files.

Ethics approval and consent to participate

No need approval from the ethical committee. Because of no primary data was collected.

Consent for publication

Not applicable.

\section{Competing interests}

The author declares that, no competing interests.

\section{Author details}

'Department of Surgical Nursing, School of Nursing, College of Medicine and Health Sciences, University of Gondar, Gondar, Ethiopia. ${ }^{2}$ Department of Pediatrics and Child Health Nursing, School of Health Sciences, College of Medicine and Health Sciences, Bahir Dar University, Bahir Dar, Ethiopia.

Received: 11 August 2020 Accepted: 30 November 2020

Published online: 09 December 2020

\section{References}

1. Solak AK, Pandza H, Beciragic E, Husic A, Tursunovic I, Djozic H. Elective case cancellation on the day of surgery at a general Hospital in Sarajevo. Mater Soc. 2019;31(1):49

2. Dimitriadis $\mathrm{P}$, lyer $\mathrm{S}$, Evgeniou $\mathrm{E}$. The challenge of cancellations on the day of surgery. Int J Surg. 2013;11(10):1126-30.

3. Ebirim L, Buowari D, Ezike H. Causes of cancellation of elective surgical operations at a university teaching hospital. J Med Med Sci. 2012;3(5): 297-301.

4. Garg R, Bhalotra AR, Bhadoria P, Gupta N, Anand R. Reasons for cancellation of cases on the day of surgery-a prospective study. Indian J Anaesth. 2009; 53(1):35.

5. Jonnalagadda R, Walrond E, Hariharan S, Walrond M, Prasad C. Evaluation of the reasons for cancellations and delays of surgical procedures in a developing country. IJCP. 2005;59(6):716-20.

6. Vinukondaiah K, Ananthakrishnan N, Ravishankar M. Audit of operation theatre utilization in general surgery. Natl Med J India. 2000:13(3):118-20

7. Miller GG. Waiting for an operation. Parents' perspectives. Can J Surg. 2004; 47(3):179.

8. Nanjappa B, Kabeer KK, Smile SR. Elective surgical case cancellation. IJCRR. 2014:6(24):19.

9. Ojo E, Ihezue C. An audit of day case cancellations in a Nigerian tertiary hospital based day case unit. ECAJS. 2008;13(2):150-3.

10. Kolawole IK, Bolaji BO. Reasons for cancellation of elective surgery in Ilorin. Niger J Surg. 2002;4(1):28-33

11. Maimaiti N, Rahimi A, Aghaie LA. Economic impact of surgery cancellation in a general hospital, Iran. EJHD. 2016;30(2):94-8.

12. Rai M, Pandit J. Day of surgery cancellations after nurse-led pre-assessment in an elective surgical Centre. The first 2 years. JCA. 2003;58(7):692-9. 
13. Kumar R, Gandhi R. Reasons for cancellation of operation on the day of intended surgery in a multidisciplinary 500 bedded hospital. J Anaesthesiol Clin Pharmacol. 2012;28(1):66.

14. Hovlid E, Bukve O, Haug K, Aslaksen AB, von Plessen C. A new pathway for elective surgery to reduce cancellation rates. BMC Health Serv Res. 2012; 12(1):154.

15. Argo JL, Vick CC, Graham LA, Itani KM, Bishop MJ, Hawn MT. Elective surgical case cancellation in the veterans health administration system. Identifying areas for improvement. AJS. 2009;198(5):600-6.

16. Chiu C, Lee A, Chui P. Cancellation of elective operations on the day of intended surgery in a Hong Kong hospital: point prevalence and reasons. Hong Kong Med J. 2012;18(1):5-10.

17. Azza A, Arwa A, Reem S. On-the-day of surgery cancellations of elective inpatient surgeries in king Fahd specialist Hospital in Dammam, Kingdom of Saudi Arabia. JKAU: Med Sci. 2013;20(2):33.

18. Mesmar M, Shatnawi N, Faori I, Khader Y. Reasons for cancellation of elective operations at a major teaching referral hospital in Jordan. East Mediterr Health J. 2011;17(8):651-5.

19. Rahimi A, Maimaiti N, Aghaei LA. Reasons for surgery cancellation in a public hospital in Iran. MJPHM. 2017;17(2):29-34.

20. Rajaguru PP, Jusabani MA, Massawe $H$, Temu R, Sheth NP. Understanding surgical care delivery in Sub-Saharan Africa. A cross-sectional analysis of surgical volume, operations, and financing at a tertiary referral hospital in rural Tanzania. Health Res Policy Syst. 2019;4(1):30.

21. Prin M, Eaton J, Mtalimanja O, Charles A. High elective surgery cancellation rate in Malawi primarily due to infrastructural limitations. WJSUDI. 2018; 42(6):1597-602.

22. Mutwali IM, Abbass AM, Elkheir IS, Arbab SS, Bur A, Geregandi T. Cancellation of elective surgical operations in a teaching hospital at Khartoum Bahri, Sudan. Sudan Med Monit. 2016;11(2):45.

23. Okeke C, Obi A, Tijani K, Eni U, Okorie C. Cancellation of elective surgical cases in a Nigerian teaching hospital. Frequency and reasons. Niger J Clin Pract. 2020;23(7):965

24. Bekele M, Gebru S, Mesai D. A cross-sectional study investigating the rate and determinants of elective case cancellations at St. Paul's Hospital Millennium Medical College, Addis Ababa, Ethiopia. ECAJS. 2020;25(2). Retrieve from https://www.google.com/search?sxsrf=ALeKk00K_rapm3gc12 znDZX0NfrdhOBu4w\%3A1607227752031\&ei=aFnMX9vEAe6m1fAP YWkmAc\&q=Bekele+M\%2C+Gebru+S\%2C+Mesai+D.+A+crosssectional+ study+investigating+the+rate+and+determinants+of+elective+case+ cancellations.

25. Ayele A, Weldeyohannes M, Tekalegn Y. Magnitude and reasons of surgical case cancellation at a specialized Hospital in Ethiopia. J Anesth Clin Res. 2019;10(927):2

26. Liberati A, Altman DG, Tetzlaff J, Mulrow C, Gøtzsche PC, loannidis JP, et al. The PRISMA statement for reporting systematic reviews and meta-analyses of studies that evaluate health care interventions: explanation and elaboration. PLoS Med. 2009;6(7):e1000100.

27. Pearson A, Wiechula R, Court A, Lockwood C. The JBI model of evidencebased healthcare. Int J Evid Based Healthc. 2005;3(8):207-15.

28. DerSimonian R, Kacker R. Random-effects model for meta-analysis of clinical trials: an update. Contemp Clin Trials Commun. 2007;28(2):105-14.

29. Higgins JP, Thompson SG, Deeks JJ, Altman DG. Measuring inconsistency in meta-analyses. BMJ. 2003;327(7414):557.

30. Peters JL, Sutton AJ, Jones DR, Abrams KR, Rushton L. Comparison of two methods to detect publication bias in meta-analysis. JAMA. 2006; 295(6):676-80.

31. Gebresellassie HW, Tamerat G. Audit of surgical services in a teaching hospital in Addis Ababa, Ethiopia. BMC Res Notes. 2019;12(1):1-5.

32. Haile $M$, Desalegn N. Prospective study of proportions and causes of cancellation of surgical operations at Jimma University teaching hospital, Ethiopia. Int J Anesth Res. 2015;3(2):87-90.

33. Desta M, Manaye A, Tefera A, Worku A, Wale A, Mebrat A, et al. Incidence and causes of cancellations of elective operation on the intended day of surgery at a tertiary referral academic medical center in Ethiopia. Patient Saf Surg. 2018;12(1):1-6.

34. Marcario A. Are your hospital operating rooms "efficient". Anesthesiology. 2006;2:233-43

35. Ogwal A, Oyania F, Nkonge E, Makumbi T, Galukande M. Prevalence and predictors of cancellation of elective surgical procedures at a Tertiary Hospital in Uganda. A Cross-Sectional Study. Surgery Research and Practice.
2020;2020. Retrieved from https://www.google.com/search?sxsrf= ALeKk00fzJ_OXmWd4vdGzsTk3voxUR_dgA\%3A1607228755166\&ei=U13 MX7PTCYCo1fAPwsmHwA0\&q=Ogwal+A\%2C+Oyania+F\%2C+Nkonge+E\%2 C+Makumbi+T\%2C+Galukande+M.+Prevalence+and+predictors+of+ cancellation.

36. Xue W, Yan Z, Barnett R, Fleisher L, Liu R. Dynamics of elective case cancellation for inpatient and outpatient in an academic center. J Anesth Clin Res. 2013;4(5):314

37. Cihoda JH, Alves JR, Fernandes LA, de Souza Neto EP. The analysis for the causes of surgical cancellations in a Brazilian university hospital. Health Care Manag Rev. 2015;16(1):41-7.

38. Obstetricians ACo, Gynecologists. ACOG Committee Opinion. Patient safety in the surgical environment. Obstet Gynecol. 2006;107(2 Pt 1):429.

\section{Publisher's Note}

Springer Nature remains neutral with regard to jurisdictional claims in published maps and institutional affiliations.

Ready to submit your research? Choose BMC and benefit from:

- fast, convenient online submission

- thorough peer review by experienced researchers in your field

- rapid publication on acceptance

- support for research data, including large and complex data types

- gold Open Access which fosters wider collaboration and increased citations

- maximum visibility for your research: over $100 \mathrm{M}$ website views per year

At BMC, research is always in progress.

Learn more biomedcentral.com/submissions 